\title{
THE INFLUENCE OF PCL-ZNO COATING COMPOSITION ON COATED OFFSET CARDBOARD PRINTS
}

\author{
Tomislav Cigula (D), Tomislav Hudika (D), Mihael Katana, \\ Marina Golik Krizmanić, Tamara Tomašegović (D) \\ University of Zagreb, Faculty of Graphic Arts, Zagreb, Croatia
}

\begin{abstract}
The most significant printing branch in these days is packaging printing. Packaging must primarily preserve the product from damaging, but at the same time must attract the consumers to be picked up from the shelf in the store. To ensure protective and aesthetic role of the packaging the prints are commonly coated with varnishes which will improve visual, mechanical, surface, and optical properties. In this paper a coating composed of polycaprolactone (PCL) and nanoscale $\mathrm{ZnO}$ was used to coat the offset prints on the cardboard.

The coatings were prepared by adding various weight amounts of the $\mathrm{ZnO}$ nanoparticles (weight ratios of $0.1,0.5$ and $1 \%$ ) into the mixture of PCL and ethyl-acetate. The coatings were applied onto prepared offset prints. The prints were evaluated before and after coating process by determining colour coordinates, print gloss, water vapour permeability and by calculating colour difference.

The results showed that on the uncoated paper coating with prepared OVPS did not affect the colour reproduction outside acceptable tolerance levels, except for magenta coated with $w(\mathrm{ZnO})=0.5$ and $1 \%$. The coating with prepared coatings caused almost none change of print gloss on uncoated paper, but increased the print gloss on coated paper. The water-vapor permeability was lowered on both investigated paper types but on the uncoated paper the addition of $\mathrm{ZnO}$ nanoparticles decreased barrier properties in comparison to the coating composed of only PCL. Increasing the mass of added ZnO increases barrier properties of the print on both investigated cardboards.

To conclude, this research has proved applicability of the PCL-ZnO coatings as a OVP on cardboard offset prints as it did not highly influenced colour reproduction but had decreased water vapour transmission rate. On the coated paper/cardboard one must take into account the increased colour difference of magenta and chose the ink to be closer to the target values at the beginning. In addition, to further investigate applicability in the packaging printing, further research should include investigation of resistance to ink fading in the ageing process, bending tests, adhesion etc.
\end{abstract}

Keywords: Offset printing, coating, PCL, surface free energy, colour difference, nano ZnO

\section{INTRODUCTION}

Despite the negative forecasts that entire printing industry will be declining in growth or even reduce its turnover on annual level, packaging is one of many printing branches that are growing continuously (Smithers, 2017). The main idea of packing is to preserve the product from any form of damage while maintaining the aesthetics as well to be as user friendly as possible (Kipphan, 2001). To ensure that, it is common that printed packaging is varnished with some sort of overprint varnish (OVP). Those varnishes ensure that packaging will have better mechanical, surface, optical properties and to improve the visual component like glossy effect. On the other hand, the OVP could influence the colour of the print. Another downside with existing OVPs is the lack of eco-friendly properties (Van Der Walle et al, 1999). In order to improve the "green" component of the packaging, OVPs have to be replaced (Kovačević et al, 2019; Makower, 2015; Kiphan, 2001). Biodegradable materials such as biopolymers could be used as the base for coating materials (Lavoine et al, 2016). In order to further improve functionality of the biopolymer coating, nanoparticles in designated weight ratios could be added to form a nanocomposite overprint varnish (Rastogi and Samyn, 2015). Nanoparticles have the possibility to improve wettability, strength, print gloss or resistance to UVA/UVB radiation - colour fading (Bota, 2017). Problem with commonly used OVPs is their lack of antibacterial properties specially when dealing with food items (Lavoine et al, 2016). For this paper, PCL will be used as OVP's base while nanoparticle $\mathrm{ZnO}$ will be used to improve its properties. ZnO was chosen because it is known for its antibacterial properties when dealing with human skin or in contact with food (Rastogi and Samyn, 2015). In addition, research of ZnO in nanoscale was conducted to determine its hydrophobics and resistance to UV (Ghule et al, 2006; Bota et al, 2018). In 
this paper, investigation of the optical and physical properties was conducted to evaluate applicability of the proposed coatings as an OVP.

\section{MATERIALS AND METHODS}

To investigate the influence of the $\mathrm{ZnO}$ weight ratio in the nanocomposite on the printed samples, uncoated Tauro offset paper $300 \mathrm{~g} / \mathrm{m}^{2}$ (further denominated as uncoated paper) and UMP Finesse Gloss paper (further denominated as coated paper) were chosen as the common packing substrates. The CMYK printing was conducted on sheetfed printing press KBA Rapida 105 PRO. The ink used to print the samples were quickset process commercial inks (Novavit Supreme Bio, Flintgroup) The printing process was conducted in compliance with the ISO 12647-2:2013, i.e. Fogra PSO (Sharma et al, 2005). This was done in order to ensure the ink's colorimetrical accuracy and possibility to compared measured results prior and after coating with the actual standard. The printed sample's colour properties were determined by Techkon SpectroDens spectrophotometer (Techkon, 2020).

Print gloss was determined before and after coating by means of Elcometer 407, a statistical gloss meter according to TAPPI/ANSI T 480 om-15 at 60 (Elcometer, 2010). The intensity of light depends on the measured sample and the angle of illumination. Measured angle mimics the angle of human eye and the viewed sample. The remaining part of the light penetrates into sample and is absorbed or diffused (Van Der Walle et al, 1999). At the angle of $60^{\circ}$ the surface gloss can be separated into low (<10 GU), middle (10-70 GU) and high (>70 GU) (Hunter, 2008).

The biopolymer used was the PCL (polycaprolactone) as the base of the proposed OVP. The PCL is a biodegradable polymer with a low melting point of $60^{\circ}$ Celsius. It has high level of applications and compatibility with other materials such as nanoparticles (Uglešić, 2015). The PCL (6800 Capa) was dissolved in ethyl acetate on heated magnetic stirrer in an air-tight container for approx. 120 minutes.

$\mathrm{ZnO}$ (Alfa Aesar) in the form of nanoparticle was added and homogenized into mixture with ultrasound dispenser Hirrlscher UP100H for 10 minutes at 100 amplitude and 100\% power. The weight ratios of the $\mathrm{ZnO}$ nanoparticles were $0.1 \%, 0.5 \%$ and $1 \%$. Nanocomposite OVPs were applied to printed samples using K202 Control Coater in controlled conditions defined by the ISO 187:1990 while the wet OVP's thickness was around $24 \mu \mathrm{m}$, as defined by the coating bar standard for the bar 3 (Wu and Baghdachi, 2015).

After coating, the prints were characterized as before coating process. From the acquired $L^{*} a * b^{*}$ coordinates colour difference was calculated for $\Delta \mathrm{E}_{00}$ and $\Delta \mathrm{E}_{\mathrm{ab}}$ (Sharma et al, 2015). Print gloss was also measured and compared as well.

Water-vapor permeability was determined using gravimetric cup method (water method). In this type of test the samples act as a water-vapor barrier where water is inside of the glass and this represents $100 \%$ humidity on the test start (American Society for Testing and Materials, 2016). In this research, amount of the water was $100 \mathrm{ml}$ while samples are at the distance of approx. $10 \mathrm{~mm}$ from the water surface. Samples were weighted at $0 \mathrm{~h}, 24 \mathrm{~h}$ and $48 \mathrm{~h}$. This way, the given results represents the weight change of the lost water in a given time interval. The water vapor transmission rate (WVTR) was calculated using equation (1). The results are presented in $g /$ day $^{*} \mathrm{~m}^{2}$ :

WVTR $=m_{0}-\frac{m_{2}+m_{g}}{2}$

where mo represents the sample mass at the beginning, $\mathrm{m}_{2}$ and $\mathrm{m}_{3}$ are sample mass after 24 and $48 \mathrm{~h}$, respectively. Only one ink was measured due to the fact that all OVPs should act as an impregnation overtop layer regardless of the ink bellow (Bota et al, 2018).

\section{RESULTS}

With measured $L^{*} a^{*} b^{*}$ values it was possible to detect the colour change and dependence of the colour to the increasement of the nanoparticle weight ration. Furthermore, by calculating colour difference $\Delta E_{00}$ and $\Delta \mathrm{E}_{\mathrm{ab}}$ (Mokrzycki and Tatol, 2011) which were used to determine colour difference between samples and compliance of the coated prints to the Fogra PSO $\left(\Delta \mathrm{E}_{\mathrm{ab}}<5\right)$ (Sharma et al, 2005) .

In Figure 1. one can see $\Delta E_{a b}$ diagram for prints on the uncoated paper. The colour difference was calculated between predefined colour coordinates (Fogra PSO) and average colour coordinates measured on samples. On the $\mathrm{x}$ axe samples are denominated to the weight ratio of the $\mathrm{ZnO}$ in a coating, while Printed sample means print without the OVP. 
It can be noticed that $\Delta \mathrm{E}_{\mathrm{ab}}$ on uncoated paper type remained under 5 for all samples after varnishing. The values of $\Delta \mathrm{E}_{\mathrm{ab}}$ on printed samples after initial varnishing (PCL $0 \%$ ) for cyan, yellow and black decreased while magenta experienced increase, with the exception of the sample coated with PCL-1\% ZnO. Generally, colour coordinates of magenta experiences smallest change while black experiences largest. It can be also noted that the increase of nanoparticles concentration did not influenced the colour significantly. As the uncoated paper is rough and absorptive it absorbs prepared coating reducing its influence on the optical properties of the print.

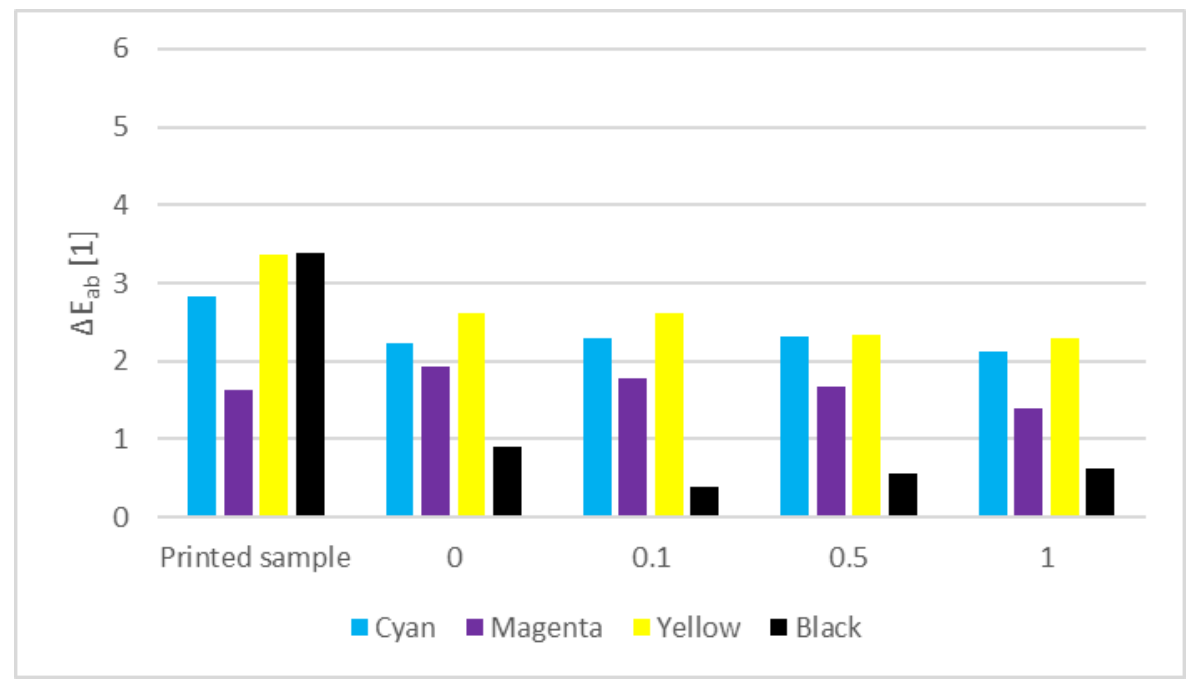

Figure 1: Colour difference $\Delta E_{a b}$ to the Fogra PSO predefined values on the uncoated paper

The difference between samples was determined by calculating $\Delta \mathrm{E}_{00}$, a formula developed to be more in compliance to human visual experience of colour difference. The calculations are made between printed sample (without OVP) and coated samples. As it can be seen in Figure 2, the added nanoparticles do affect the colour reproduction but in very small scale. The results of the difference $\Delta \mathrm{E}_{00}$ show that adding $\mathrm{ZnO}$ nanoparticles decrease the colour difference in comparison to the printed sample coated only by $\mathrm{PCL}$ coating. The only colour which is highly influenced by coating process is black with differences over 2, while differences by all other colours are under 1. Previous research (Golik Krizmanić, 2020) showed that PCL itself causes darkening of the print and therefore achromatic, black, colour is more influenced by this fact. Furthermore, as previously mentioned, uncoated paper is absorptive and less coating stays on the top of the printed sample.

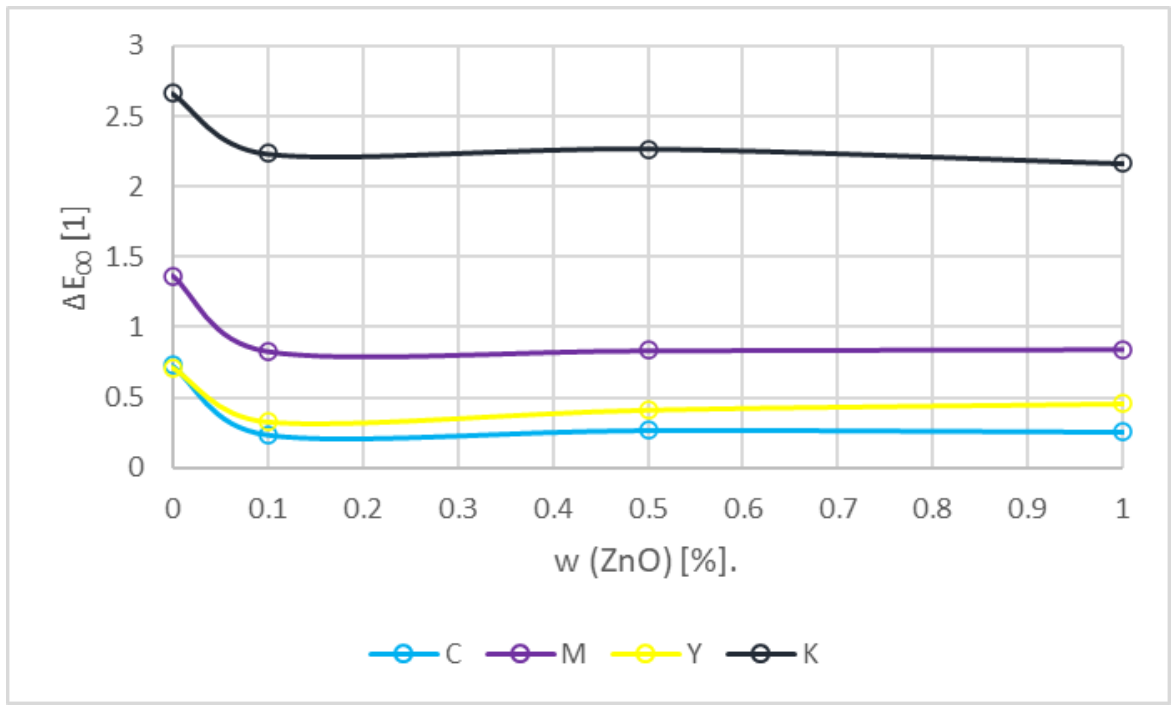

Figure 2: Colour difference $\Delta E_{00}$ to the print without coating on the uncoated paper 


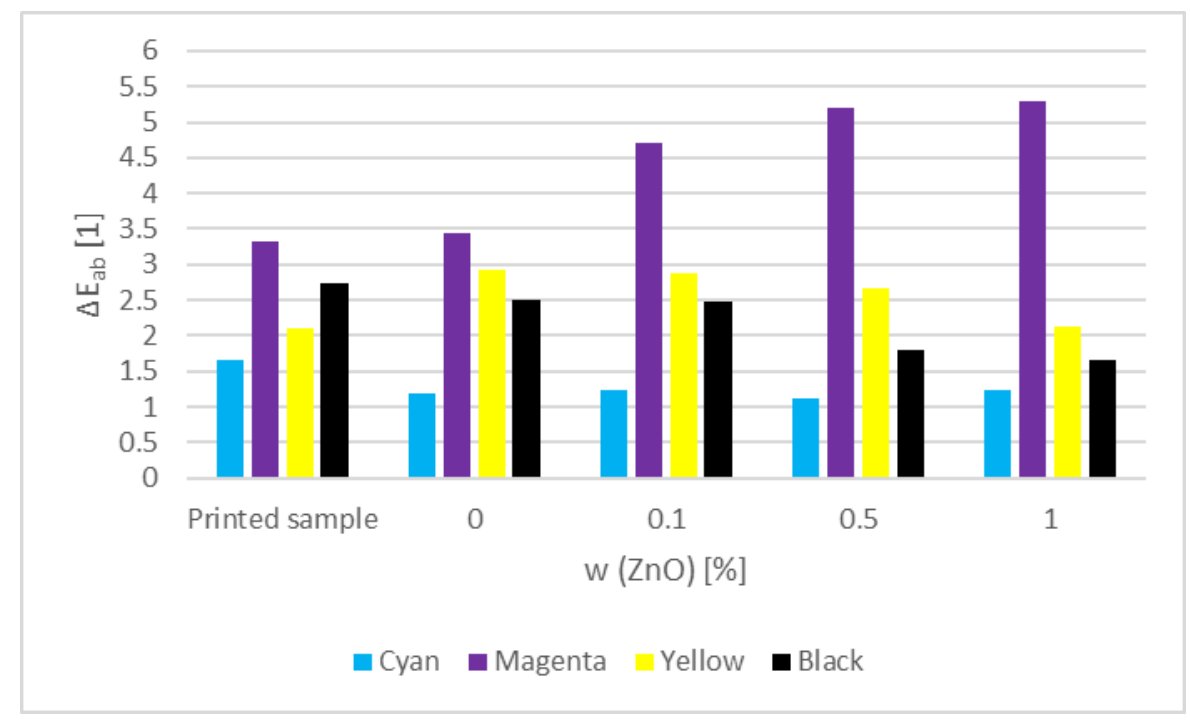

Figure 3: Colour difference $\triangle E_{a b}$ to the Fogra PSO predefined values on the coated paper

In Figure 3 diagram for $\Delta \mathrm{E}_{\mathrm{ab}}$ on coated paper can be observed. The initial printed samples have all $\Delta \mathrm{E}_{\mathrm{ab}}$ under 5 (in compliance to the Fogra PSO) while it can be seen that magenta coated with composite where nanoparticle weight ratio is $<0.5 \%$ experiences $\Delta \mathrm{E}_{\mathrm{ab}}$ over 5 which leaves it outside the defined tolerance. While observing the measured $L^{*} a^{*} b^{*}$ after varnishing one can see that magenta had primarily changed in the $b^{*}$ coordinate (target values $L^{*} a^{*} b^{*}=47,74,-5$; printed sample $L^{*} a^{*} b^{*}=46.87,74.01,-1.82$; sample coated with $\left.w(Z n O)=1 L^{*} a^{*} b^{*}=47.25,73.98,0.28\right)$. This means that original ink is moving magenta colour in $b^{*}$ coordinate which is only "improved" by the increasing ZnO weight ratio.

Although the differences to the standard are larger than the ones on the uncoated paper, observing Figure 4 one could see that colour difference between uncoated sample and the ones coated with prepared composites are smaller. The largest difference is by black while cyan and yellow are under 0.5 . It could also be noticed that increasing $\mathrm{ZnO}$ weight ratio is decreasing colour difference $\Delta \mathrm{E}_{00}$ of black, but increasing the difference of magenta. The $\mathrm{ZnO}$ influences the $\mathrm{L}^{*}$ coordinate of the black ink the most therefore increasing the lightness, i.e. compensates darkening of the image by the PCL coating. On the other side, coatings with the increase of the $\mathrm{ZnO}$ weight increase $\mathrm{b}^{*}$ coordinate of the magenta, increasing the colour difference.

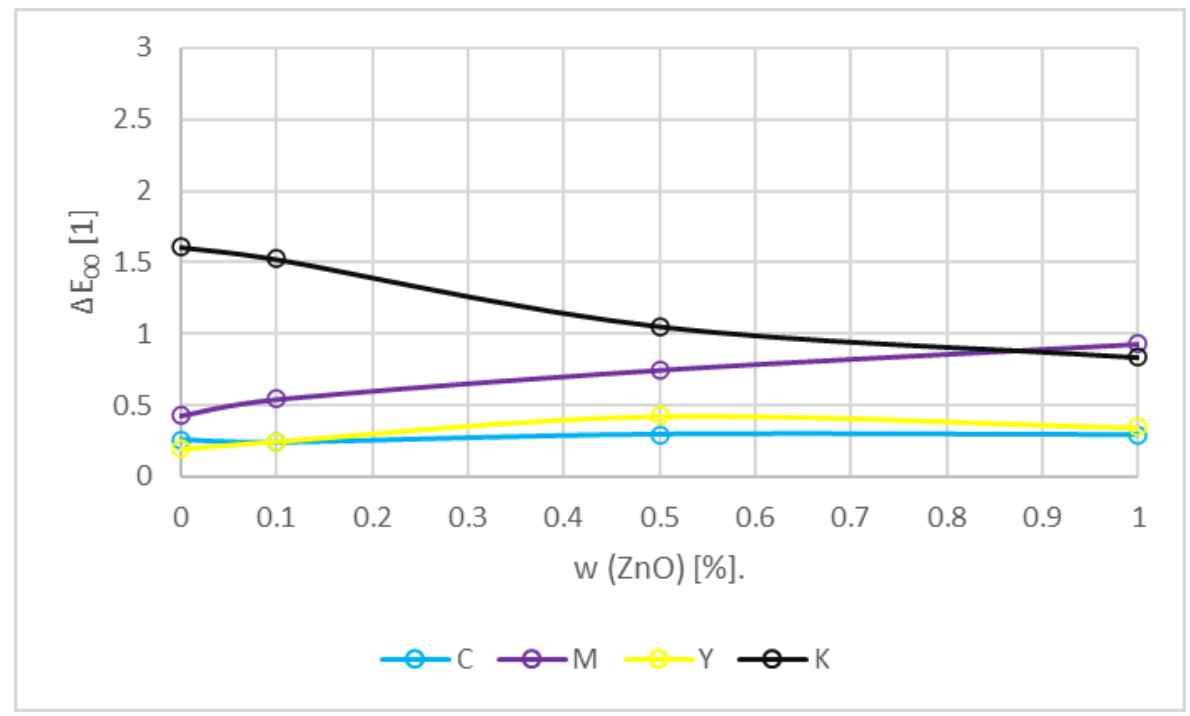

Figure 4: Colour difference $\Delta E_{00}$ to the print without coating on the coated paper

Figures 5 and 6 show difference of print gloss $(\Delta G$, equation 2$)$ on investigated samples. The initial value of gloss on uncoated paper is very low $(\approx 5 \mathrm{GU})$ while on the coated paper is cca. $60 \mathrm{GU}$. 
$\Delta G=\frac{G_{P S}}{G_{O V P}}$

where Gps is gloss of the printed sample and Govp is gloss of the coated samples.

On diagram presented in Figure 5 it can be seen that print gloss on the uncoated paper is unchanged regardless of the composition of the coating. As seen on the colour change, the uncoated paper's absorption means less coating stays on the surface of the print and therefore has lower influence on the surface properties. On the other hand, on the coated paper the increased concentration of the added $\mathrm{ZnO}$ particles leads to the increase of the print gloss on samples (Figure 6). The increase is highest on the magenta while on the cyan it is the same or slightly increased with the coating in which $w(Z n O)=1 \%$. This can be attributed to the already glossy surface and saturation of polymer matrix with increase of the nanoparticle weight ratio (Bota, 2017).

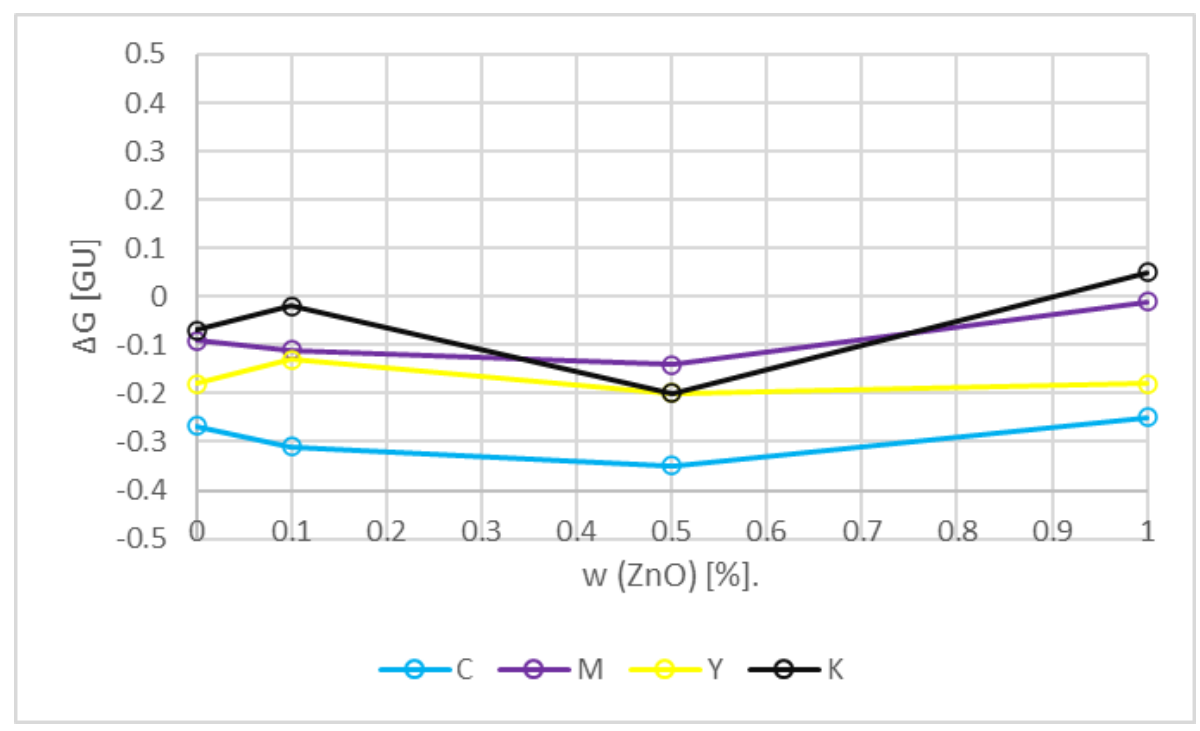

Figure 5: Difference of print gloss between print with and without coating on the uncoated paper

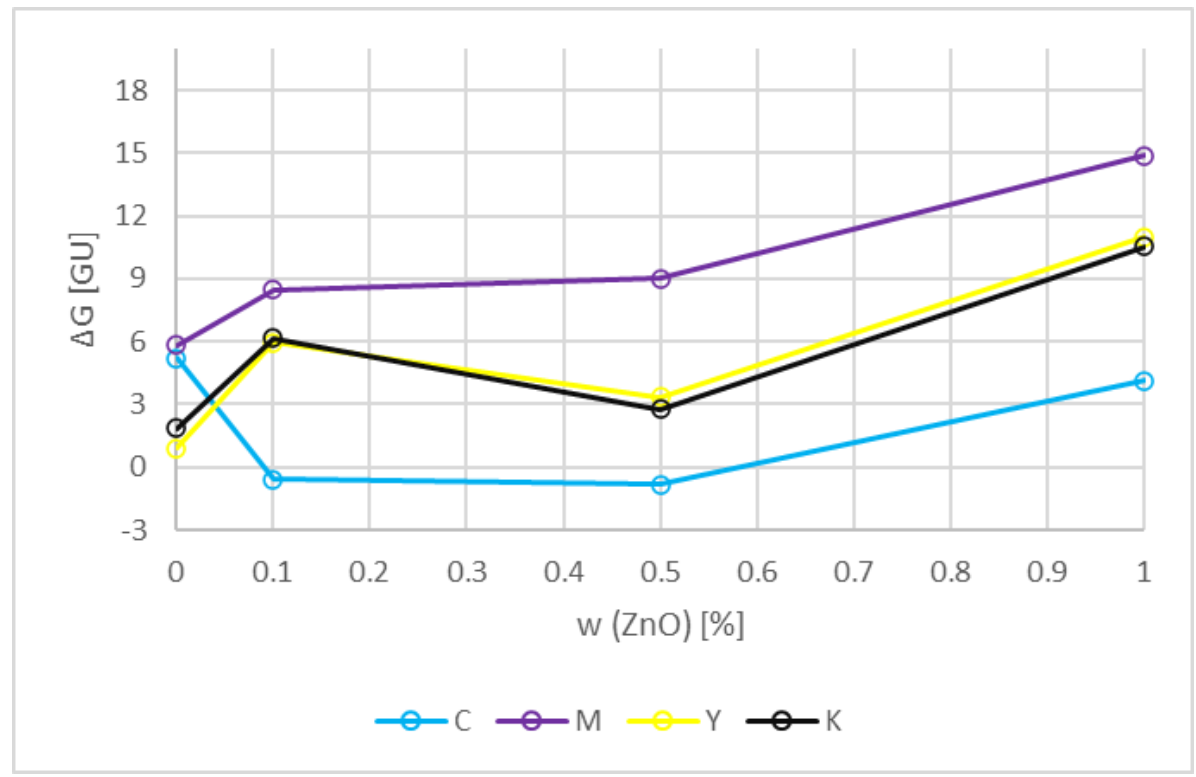

Figure 6: Difference of print gloss between print with and without coating on the coated paper

Water-vapor permeability is one of the ways to measure the quality and efficiency of the packaging material. The samples were weighed at the beginning of the test, and then after $24 \mathrm{~h}$ and $48 \mathrm{~h}$. Diagrams in Figures 7 and 8 show water vapour permeability of prepared sample, where on the $x$-axe are samples 
denominated as printed sample means uncoated print, while 0 means print coated with PCL, $0.1,0.5$ and 1 mean prints coated with composites of $\mathrm{PCL}$ with various weight ratio of $\mathrm{ZnO}(0.1,0.5$ and $1 \%)$.

In Figure 7 one can see that the permeability decreases with the nanocomposite application on uncoated paper. The printed uncoated sample has very high wettability level as well as very high permeability to water-vapor due to its surface properties. The nanocomposite impregnates the surface in some amount and the best result, i.e. the lowest water vapour permeability is achieved by PCL coating. Addition of the $\mathrm{ZnO}$ at the lowest weight ratio decreased barrier property of the print, but it could be seen that increasing the weight ratio increases the barrier properties. This is probably the consequence of nanoparticle penetration in the sample surface, where it weakens the polymer matrix. With the increase of nanoparticle concentration this effect is compensated, as it can be seen on $0.5 \%$ and $1 \%$ of the concentration.

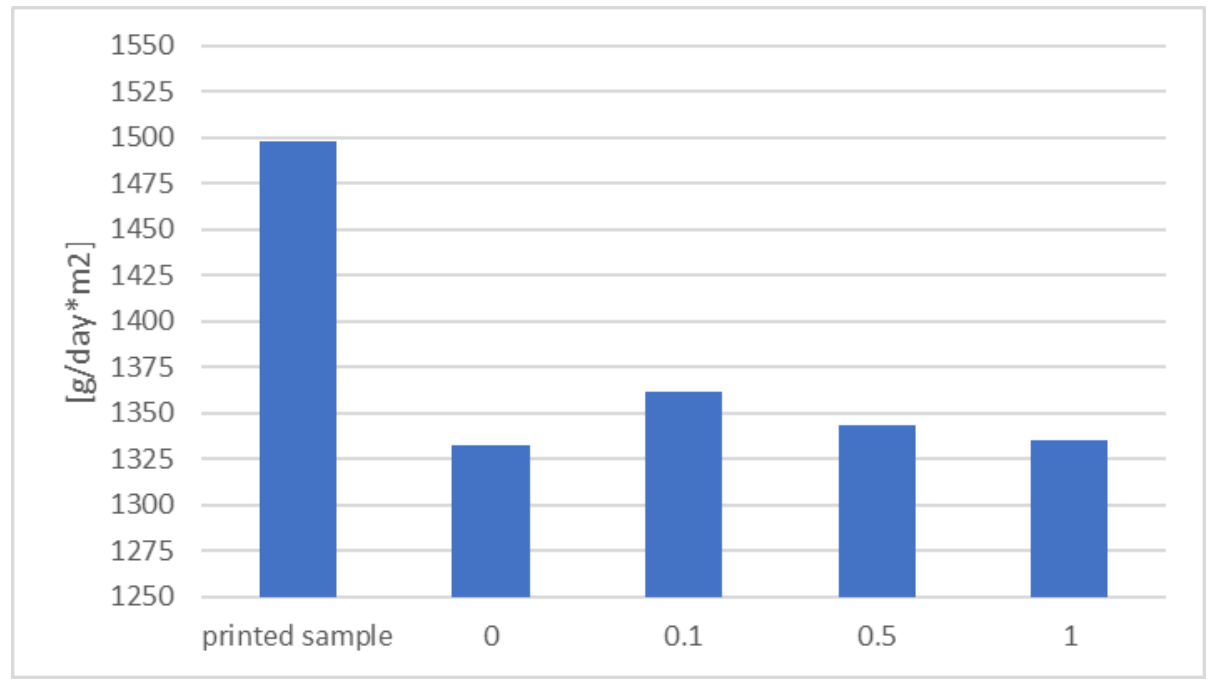

Figure 7: Water vapour transmission rate of prints on the uncoated paper

On the coated paper, similar trend could be noticed when it comes to permeability after varnishing, i.e. the PCL coating shows lower permeability than the coating which has $w(Z n O)=0.1 \%$ particles, but increasing weight ratio of $\mathrm{ZnO}$ decreases permeability to water vapour (Figure 8). It could be seen on both papers that the reduction of the transmission rate is almost the same $\left(\approx 165 \mathrm{~g} / \mathrm{daym}^{2}\right)$ which shows much higher effectiveness on the coated paper as the initial value is much lower.

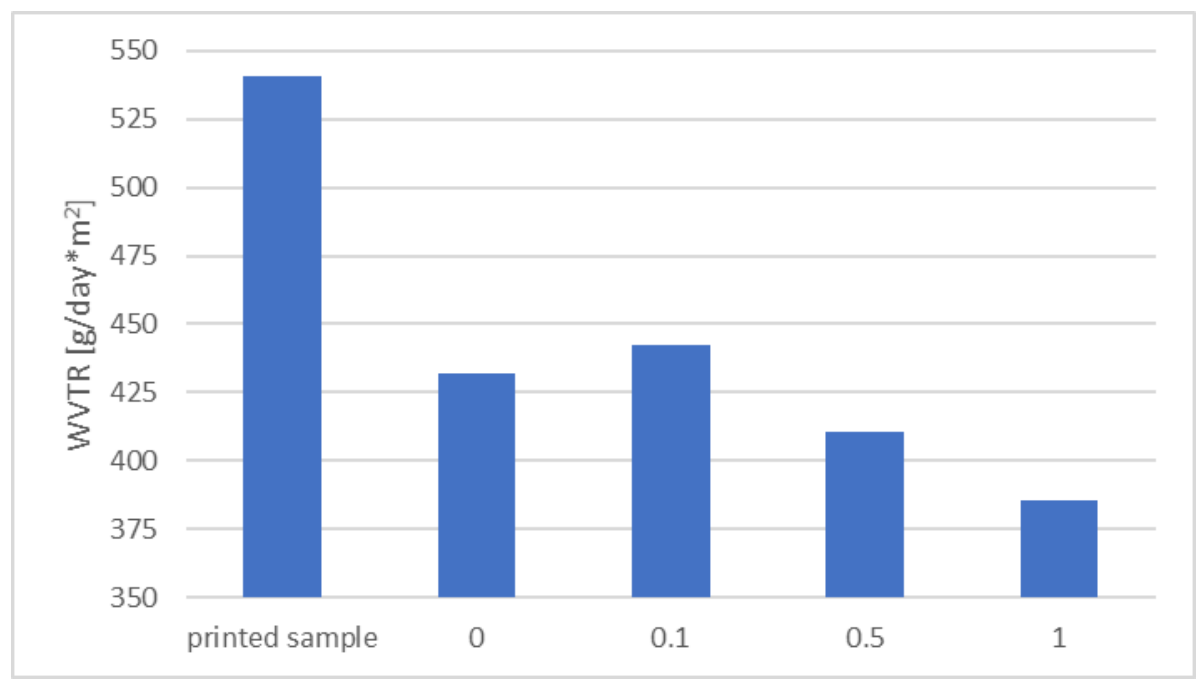

Figure 8: Water vapour transmission rate of prints on the coated paper 


\section{CONCLUSION}

The aim of this paper was to assess the influence of nanocomposite PCL-ZnO in different composition (by varying weight ratio of $\mathrm{ZnO}$ nanoparticles) on printed sample's properties. To conduct this experiment, uncoated offset paper and gloss coated paper were chosen as they are used as the common packaging material. The samples were printed via offset printing technique on KBA Rapida 105 PRO printing machine in ordinance with ISO 12647-2:2013, i.e. Fogra PSO. The samples were coated with prepared nanocomposite OVPs (PCL-ZnO).

The results showed that on the uncoated paper coating with prepared OVPs did not affect the colour reproduction outside acceptable tolerance levels. On the coated paper the coatings in which weight ratio of $\mathrm{ZnO}$ was 0.5 and 1\% caused magenta to be outside acceptable tolerance level. On the other hand, it could be seen that weight ratio of $\mathrm{ZnO}$ causes lower colour differences to the original print on coated paper.

Applying the prepared coatings caused almost none change of print gloss on uncoated paper, but increased the print gloss on coated paper

The water-vapor permeability was lowered on both investigated paper types but on the uncoated paper adding ZnO nanoparticles decreased barrier properties in comparison to the coating composed of PCL only. Increasing the mass of added ZnO increases barrier properties of the print on both investigated cardboards.

This research has proved applicability of the PCL-ZnO coatings as a OVP on cardboard offset prints as it did not highly influenced colour reproduction but has decreased water vapour transmission rate. On the coated paper/cardboard one must take into account increased colour difference of magenta and chose the ink which will be reproduced closer to the standardized colorimetric values or add lower concentration of the nanoparticles without decreasing their role in the coating. In addition, to further investigate the applicability in the packaging printing, further research should include investigation of resistance to ink fading in the ageing process, bending tests, adhesion etc.

\section{ACKNOWLEDGMENTS}

This research is part of the project UIP-2017-05-4081, "Development of the model for production efficiency increase and functionality of packaging", supported by Croatian Science Foundation. It is also supported by University of Zagreb short term funding "Development and modification of composite coatings on packaging printing substrates".

\section{REFERENCES}

[1] American Society for Testing and Materials, ASTM E96/E96M-16 Standard Test Methods for Water Vapor Transmission of Materials, ASTM International, 2016. doi: 10.1520/E0096_E0096M-16.

[2] Bota, J., Vukoje, M., Brozovic, M., Hrnjak-Murgic, Z.: "Reduced water permeability of biodegradable PCL nanocomposite coated paperboard packaging", Chemical and Biochemical Engineering Quarterly 31, 417-424, 2018. doi: 10.15255/CABEQ.2017.1126.

[3] Bota, J.: "Optimisation of Coated Paperboard Packaging Properties According to Design", PhD thesis, University of Zagreb Faculty of Graphic Arts, 2017.

[4] Elcometer: "Elcometer 407 operating manual", URL: https://www.elcometer.com/images/stories/PDFs/InstructionBooks/407.pdf (last request: 2020-0918), 2010.

[5] Ghule, K., Ghule, V., Chen, J., Ling, C.: "Preparation and characterization of ZnO nanoparticles coated paper and its antibacterial activity study", Green Chemistry 8, 1034-41, 2018. doi: 10.1039/B605623G.

[6] Golik Krizmanić, M.: "Functional PCL coating with the addition of $\mathrm{ZnO}$ nanoparticles as print protection", BSc thesis, University of Zagreb Faculty of Graphic Arts, 2020.

[7] Hunter, R.: "Methods of determining gloss", Journal of Research of the National Institute of Standards and Technology 18, 14-16, 2008.

[8] Kipphan, H.: "Handbook of Print Media", (Springer-Verlag, Berlin, 2001.), pages 206-224. doi: 10.1007/978-3-540-29900-4. 
[9] Kovačević, D., Brozović, M., Itrić Ivanda, K.: "Eco-mark on product packaging and its effect on the perception of quality", Journal of Graphic Engineering and Design 10 (2), 17-24, 2019. doi: 10.24867/JGED-2019-2-017.

[10] Lavoine, N., Guillard, V., Desloges, I., Gontard, N., Bras, J.: “Active bio-based food-packaging: Diffusion and release of active substances through and from cellulose nanofiber coating toward food-packaging design", Carbohydrate Polymer Technologies and Applications 149, 40-50, 2016. doi: 10.1016/j.carbpol.2016.04.048.

[11] Makower, J.: "How green printing can make a good impression", URL: https://grist.org/article/printing/ (last request: 2020-09-20), 2006.

[12] Mokrzycki, W., Tatol, M.: "Color difference Delta E-A survey Colour difference $\Delta E-A$ survey", Machine Vision and Applications 1, 14-18, 2014.

[13] Rastogi, V., Samyn, P.: "Bio-based coatings for paper applications", Coatings 5, 887-930, 2015. doi: 10.3390/coatings5040887.

[14] Sharma, G., Wu, W., Dalal, E.: "The CIEDE2000 color-difference formula: Implementation notes, supplementary test data, and mathematical observations", Color Research and Application 30, 2130, 2005. doi: 10.1002/col.20070.

[15] Smithers: "Inkjet printing builds towards $\$ 100$ billion market", URL: https://www.smithers.com/resources/2018/oct/inkjet-printing-builds-towards-\$100-billion-market (last request: 2020-06-20), 2017.

[16] Techkon: "Spectro-Densitometer SpectroDens", URL: https://www.techkon.com/files/downloads/prospekte/SpectroDens\%20Manual\%20Web.pdf (last request: 2020-09-17), 2020.

[17] Uglešić, P.: "Biodegradable polymers and their application", BSc thesis, University of Zagreb Faculty of Chemical Engineering, 2015.

[18] Van Der Walle, G., Buisman, H., Weusthuis, A., Eggink, G.: "Development of environmentally friendly coatings and paints using medium-chain-length poly(3-hydroxyalkanoates) as the polymer binder", International Journal of Biological Macromolecules 25, 123-8, 1999. doi: 10.1016/S01418130(99)00025-2.

[19] Wu, L., Baghdachi, J.: "Functional Polymer Coatings: Principles, Methods, and Applications", Wiley, Hoboken NJ, 2015.), pages 134-155. doi: 10.1002/9781118883051.

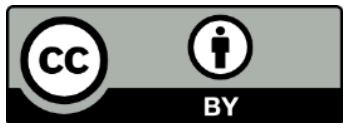

(C) 2020 Authors. Published by the University of Novi Sad, Faculty of Technical Sciences, Department of Graphic Engineering and Design. This article is an open access article distributed under the terms and conditions of the Creative Commons Attribution license 3.0 Serbia (http://creativecommons.org/licenses/by/3.0/rs/). 